\title{
Clonal selection drives protective memory B cell responses in controlled human malaria infection
}

\author{
Rajagopal Murugan, ${ }^{1 *}$ Lisa Buchauer, ${ }^{2,3,4 *}$ Gianna Triller, ${ }^{1}$ Cornelia Kreschel, ${ }^{5}$ Giulia Costa, ${ }^{5}$ \\ Gemma Pidelaserra Martí, ${ }^{1,4}$ Katharina Imkeller, ${ }^{1,4}$ Christian E. Busse, $^{1}$ Sumana Chakravarty, ${ }^{6}$ \\ B. Kim Lee Sim, ${ }^{6}$ Stephen L. Hoffman, ${ }^{6}$ Elena A. Levashina, ${ }^{5}$ Peter G. Kremsner, ${ }^{7}$ \\ Benjamin Mordmüller, ${ }^{7}$ Thomas Höfer, ${ }^{2,3 \dagger}$ Hedda Wardemann ${ }^{1 \dagger}$
}

\begin{abstract}
Affinity maturation, the clonal selection and expansion of antigen-activated B cells expressing somatically mutated antibody variants that develop during $\mathrm{T}$ cell-dependent germinal center reactions, is considered pivotal for efficient development of protective $B$ cell memory responses to infection and vaccination. Repeated antigen exposure promotes affinity maturation but each time also recruits antigen-reactive naïve $B$ cells into the response. Here, we determined the relative impact of affinity maturation versus antigen-mediated clonal selection of naïve $B$ cells to mount potent B cell memory responses in humans after repeated exposure to a complex pathogen, the malaria parasite Plasmodium falciparum (Pf). Using single-cell immunoglobulin (Ig) gene sequencing and production of recombinant monoclonal antibodies, we analyzed the origin, development, and quality of memory $B$ cell responses to Pf circumsporozoite protein (PfCSP), the major sporozoite surface protein. We show that after repeated immunization of Pf-naïve volunteers with infectious Pf sporozoites (PfSPZ Challenge) under chloroquine prophylaxis (PfSPZ-CVac), the clonal selection of potent germline and memory B cell precursors against the central PfCSP NANP repeat outpaces affinity maturation because the majority of Ig gene mutations are affinity-neutral. Mathematical modeling explains how the efficiency of affinity maturation decreases strongly with antigen complexity. Thus, in the absence of long-term exposure, the frequency of antigen-reactive precursors and likelihood of their activation rather than affinity maturation will determine the quality of anti-PfCSP memory B cell responses. These findings have wide implications for the design of vaccination strategies to induce potent $B$ cell memory responses against PfCSP and presumably other structurally complex antigens.
\end{abstract}

\section{INTRODUCTION}

A hallmark of B cell immune responses is the improvement of antigen receptor affinity over time. Two mechanisms could contribute to this affinity improvement. First, on the population level, rare high-affinity precursors could be selected from the naïve B cell repertoire $(1,2)$. Second, on the level of antigen-activated clones, random immunoglobulin (Ig) gene somatic hypermutations (SHMs) and positive selection of B cells expressing affinity-improved antibody variants could lead to affinity maturation during germinal center (GC) reactions $(3,4)$. Affinity maturation has been extensively studied using haptens (small model antigens) in mice, but little is known about the contributions of affinity maturation and clonal selection in natural immune responses (4-8).

Here, we set out to address this fundamental question in a recent human Plasmodium falciparum (Pf) malaria immunization trial with PfSPZ-CVac [Pf sporozoites (SPZ) Chemoprophylaxis Vaccine] (9). Pf is a complex eukaryotic parasite that causes often life-threatening malaria disease. Natural transmission of Pf sporozoites to humans occurs through the bite of infected Anopheles mosquitoes. From the skin, the parasites travel to the liver via the bloodstream. After extensive

${ }^{1}$ B Cell Immunology, German Cancer Research Center, Heidelberg, Germany. ${ }^{2}$ Theoretical Systems Biology, German Cancer Research Center, Heidelberg, Germany. ${ }^{3}$ BioQuant Center, University of Heidelberg, Heidelberg, Germany. ${ }^{4}$ Faculty of Biosciences, University of Heidelberg, Heidelberg, Germany. ${ }^{5}$ Vector Biology Unit, Max Planck Institute for Infection Biology, Berlin, Germany. 'Sanaria Inc., Rockville, MD 20850, USA. ${ }^{7}$ Institute of Tropical Medicine and German Center for Infection Research, University of Tübingen, Tübingen, Germany.

*These authors contributed equally to this work.

†Corresponding author. Email: t.hoefer@dkfz-heidelberg.de (T.H.); h.wardemann@ dkfz.de (H.W.) multiplication within hepatocytes, they differentiate into erythrocyteinvasive asexual blood stages associated with malaria symptoms. Parasite exposure of Pf-naïve volunteers by mosquito bite or by direct venous inoculation of infectious sporozoites under chemoprophylaxis prevents asexual erythrocytic blood-stage infection after controlled human malaria infection (CHMI) $(10,11)$. Protection against CHMI and naturally transmitted Pf malaria can also be achieved by vaccination with radiation-attenuated sporozoites but requires much higher numbers, presumably due to the early arrest of parasite development in the liver (11-15).

Here, to study the evolution and quality of the developing human memory B cell response, we analyzed the B cell response after repeated exposure to infectious sporozoites in individuals immunized with three doses of PfSPZ-CVac by direct venous inoculation (9). We specifically focused our analysis on the response against the major Pf sporozoite surface antigen and promising vaccine immunogen circumsporozoite protein (PfCSP), which is essential for parasite development and a target of protective antibodies (16-21).

\section{RESULTS}

Preexisting memory B cells contribute to the development of protective IgM-dominated anti-PfCSP NANP antibody responses

Nine healthy malaria-naïve volunteers received three direct venous inoculations with 51,200 infectious Pf sporozoites [Sanaria PfSPZChallenge; $(22,23)$ ] at 4-week intervals under chloroquine chemoprophylaxis (Sanaria PfSPZ-CVac; Fig. 1A), which induced protection against CHMI (9). All donors developed anti-PfCSP serum as well 

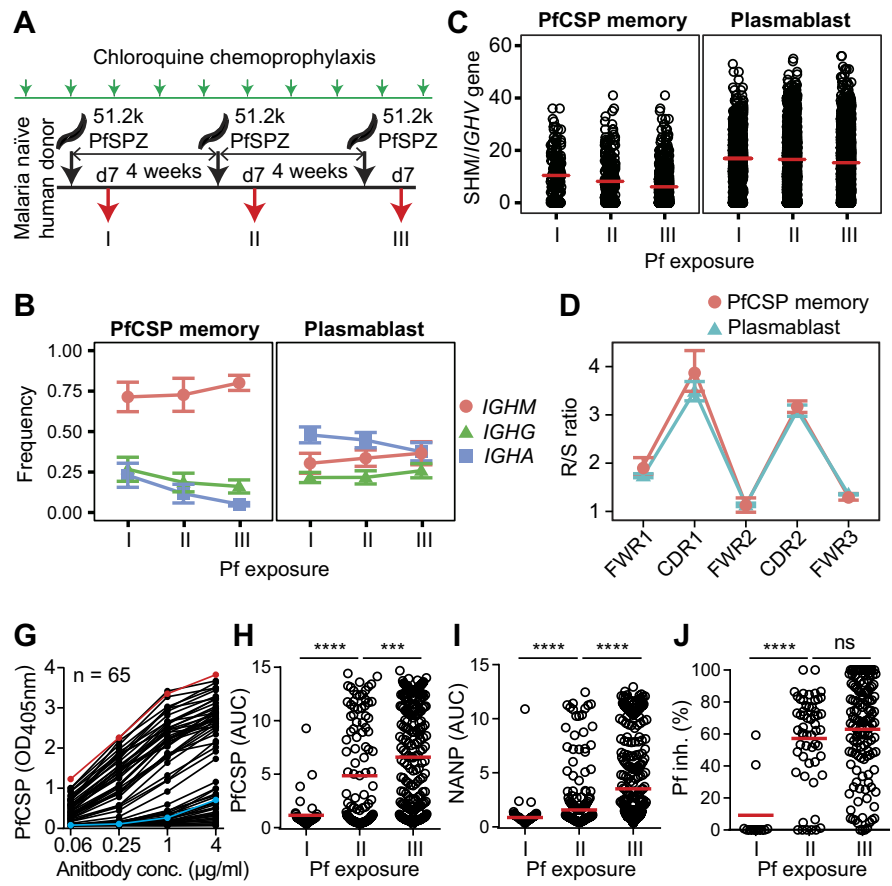

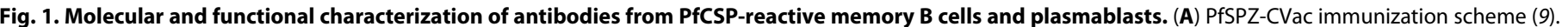

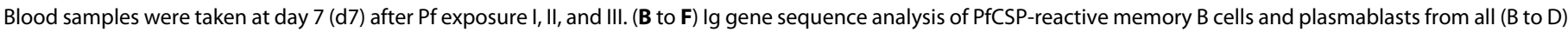

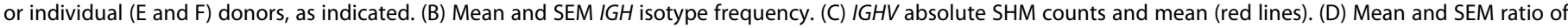

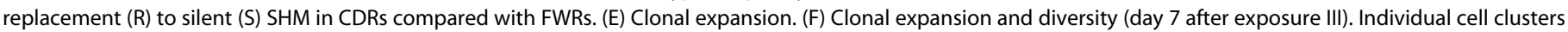

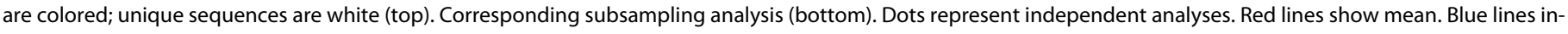

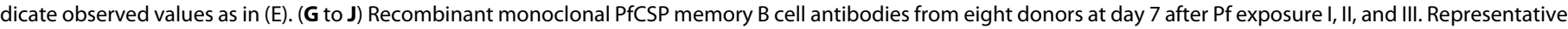

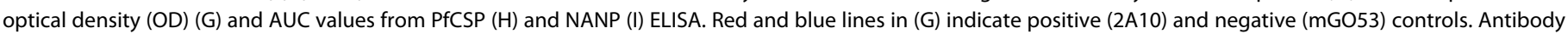

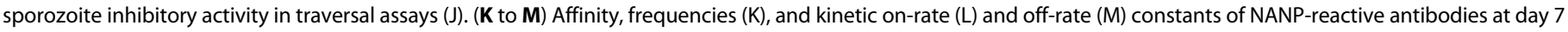

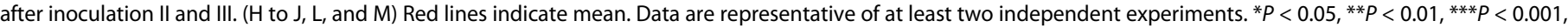
${ }^{* * * *} P<0.0001$, two tailed Mann-Whitney test $(\mathrm{H}$ to $\mathrm{J}, \mathrm{L}$, and $\mathrm{M})$ and $\chi^{2}$ test $(\mathrm{K})$. $n$ numbers are provided in tables $\mathrm{S} 1$ and $\mathrm{S} 2$. ns, not significant.

as plasmablast and PfCSP memory B cell responses, albeit at various levels and with different isotype distributions (fig. S1, A and B). Using flow cytometric cell sorting, we isolated circulating single PfCSPreactive memory $B$ cells as well as single non-antigen-selected plasmablasts at day 7 after each parasite exposure (I, II, and III; Fig. 1A, fig. S1B, and tables $\mathrm{S} 1$ and $\mathrm{S} 2$ ). Paired $I G H$ and $I G K / I G L$ gene sequence analysis on eight of nine donors (table S1) showed that the anti-PfCSP memory B cell response was strongly dominated by IgM compared with the plasmablast response (Fig. 1B). Seven days after the first infection, a large fraction of antibodies from all isotypes were encoded by highly mutated Ig genes, indicating that preexisting memory B cells had been efficiently recruited into the anti-PfCSP memory B cell and even more so into the plasmablast responses (Fig. 1C and fig. S2A). The level of SHM was comparable with the level observed in non-antigenenriched circulating IgM, IgG, and IgA memory B cell populations from healthy European donors, as previously reported (24-27). This finding was unexpected, especially after the first infection, because the donors had no history of Pf exposure at this time point (9). Several of these mutated B cell clones expanded and persisted, suggesting that they played an active role in the anti-Pf response (table S3). Independently, the frequency of B cells expressing germline and lowmutated antibodies increased with repeated exposure specifically in PfCSP memory B cells, leading to a drop in mean SHM predominantly in IgG1 and IgG3 antibodies (Fig. 1C and fig. S2B). We also identified numerous clonally expanded germline and low diversified IgM and IgG PfCSP memory B cells (table S3) that likely originated from newly activated naïve precursors and underwent class-switch recombination and SHM diversification presumably in GCs (fig. S2, C and D). In some cases, the precursor $B$ cells of expanded and diversified clusters differentiated into both memory B cells and plasmablasts as indicated by the presence of clonally related members in both cell compartments (fig. S2E). In all donors, PfCSP memory B cells and plasmablasts showed high ratios of replacement to silent mutations in the antigen-binding complementarity determining regions (CDRs) compared with the framework regions (FWRs), indicating that the antibodies had undergone GC selection (Fig. 1D and fig. S2F). Repeated parasite exposure induced strong clonal expansion of PfCSP memory B cells only in five donors (T2_042-073) but not in the other three (T2_017-035; Fig. 1E and fig. S2G). After the third infection, clonally expanded cells represented on average $55 \%$ of the sampled PfCSP memory pool in T2_042-073 and, with the exception of donor T2_051, were highly diverse, whereas clonal expansion reached only about $6 \%$ in T2_017-035 (Fig. 1F and fig. S2, G and H). The degree of clonal expansion appeared to be lower in the plasmablast compartment, presumably because plasmablasts were not isolated on the basis of their antigen specificity (Fig. 1, E and F). To measure the quality of the antiPfCSP response over time, we expressed 422 recombinant monoclonal antibodies from PfCSP-reactive memory B cells and their related plasmablasts of all eight donors, focusing on clonally expanded memory B cells (tables S1 and S2). As expected, the mean PfCSP-binding 
quality, as measured in enzyme-linked immunosorbent assay (ELISA), increased with each infection (Fig. 1, G and H). About 35\% of antibodies, cloned after the first parasite exposure, were polyreactive (fig. S2I). The frequency was significantly lower at later time points, suggesting that polyreactive $B$ cells had a relative advantage when the overall level of PfCSP reactivity was still low. The vast majority of antibodies targeted the immunodominant NANP repeat B cell epitope (Fig. 1I). The level of PfCSP reactivity correlated directly with the degree of parasite inhibition in a standard in vitro hepatocyte traversal assay (Fig. 1J and fig. S2J). NANP-reactive antibodies showed a wide range of affinities from $10^{-5} \mathrm{M}$ to $10^{-10} \mathrm{M}$, as measured by surface plasmon resonance (SPR) to a short $\mathrm{NANP}_{5}$ epitope, reminiscent of affinity maturation to monovalent antigens with a reported affinity ceiling of $10^{-10} \mathrm{M}$ (Fig. $\left.1 \mathrm{~K}\right)(3,4,28)$. Antibodies with improved affinities accumulated over the repeated immunizations and were selected for lower off-rates while maintaining high on-rates (Fig. 1, $\mathrm{L}$ and $\mathrm{M}$ ). In summary, repeated Pf exposure in malaria-naïve volunteers induced potent Pf-inhibitory IgM-dominated anti-PfCSP responses that targeted predominantly the NANP repeat. The cells originated from polyreactive and nonpolyreactive naïve cells as well as preexisting memory B cells formed in previous nonrelated infections. Although all donors mounted prominent immune responses, only a subset exhibited PfCSP memory B cell responses associated with a high degree of clonal expansion.

\section{The anti-NANP response matures independently of efficient affinity maturation to the repeat}

We initially expected that the global increase in high-binding PfCSP memory B cell antibodies was the result of affinity maturation to the NANP repeat. To test this, we measured the $\mathrm{NANP}_{5}$ affinity of clonally expanded repeat binding antibodies from all time points including day 7 after injection of PfSPZ Challenge for CHMI (Fig. 2). Compared with their germline or near-germline counterparts with only a few mutations, the majority of SHM-diversified antibodies showed no appreciable increase in antigen binding independently of their ini-

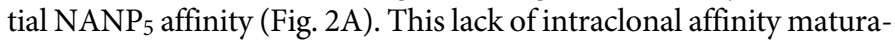
tion was confirmed by generating predicted germline ancestors of naïve and memory $B$ cell-derived clusters for which unmutated antibody variants had not been sampled (Fig. 2B). Although we identified clusters where mutants with substantially higher affinity developed, this was overall rare (Fig. 2C and fig. S3). Thus, the memory B cell response to the NANP repeats of PfCSP comprised germline and mutated clones of different antibody quality that showed little evidence of efficient affinity maturation, despite strong maturation of the response at the population level (Fig. 1, G to M).

\section{Computational modeling predicts antigen dose and repeated exposure to determine the quality of memory $B$ cell responses to $P f$}

To understand why intraclonal affinity maturation to PfCSP was so rare, we developed a computational model for the GC reaction and simulated the development of memory B cells in response to repeated parasite exposure (Fig. 3A and table S4). SHM was implemented at the natural rate of $p_{\text {mut }}=3 \times 10^{-3}$ per cell division and codon (29); subsequent selection for antibody affinity was based on competition of $\mathrm{B}$ cells for survival signals from a limiting number of $\mathrm{T}$ follicular helper $\left(\mathrm{T}_{\mathrm{FH}}\right)$ cells $(4,30)$. In the well-studied case of affinity maturation against haptens [e.g., modeled in (31)], mutations at a single key position in the antibody can increase affinity by more than an order
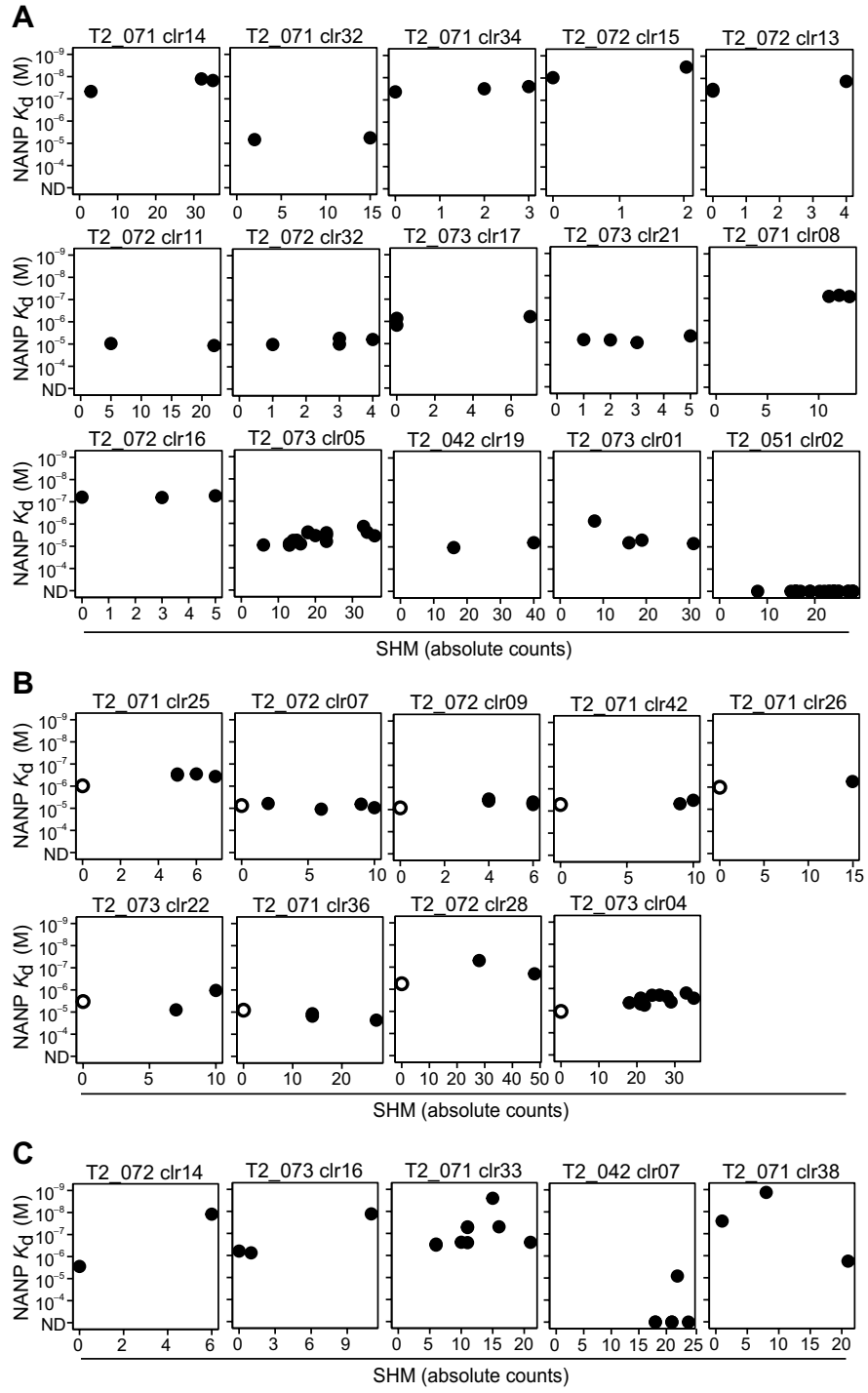

Fig. 2. Inefficient affinity maturation. (A to $\mathbf{C}) \mathrm{NANP}_{5}$ affinity for clonally related antibodies (closed circles) from the indicated clusters that do not show affinity maturation (A) including the predicted germline precursor (open circles) (B) and for $B$ cell cluster antibodies, where SHM affects their $\mathrm{NANP}_{5}$ affinity (C). Data are representative of at least two independent experiments. ND, not detectable.

of magnitude $(32,33)$. In contrast, for protein antigens, increased antibody affinity appears to require mutations at more than one key position ( $n_{\text {key }}>1$; Fig. 3B), with an incremental contribution of each key residue to antibody affinity (Fig. 3C) (34). Our recent structures of human anti-PfCSP memory antibodies induced by natural Pf exposure indicate a large number of key positions (35); accordingly, we used $n_{\text {key }}=10$ (unless indicated otherwise). On the basis of our experimental observations and recently published data (36), we seeded the GC with $~ 100$ naïve and preexisting memory B cells with a diverse repertoire and affinity in the experimentally observed range following a normal distribution with large numbers of $\mathrm{B}$ cells expressing lowaffinity antibodies in the range of $10^{-5} \mathrm{M}$ and rare high-affinity GC precursors. Using this input for simulations of individual GCs, we observed an initial highly polyclonal phase, followed by selective expansion of the best antigen binders. Concomitantly, less potent clones were 
A

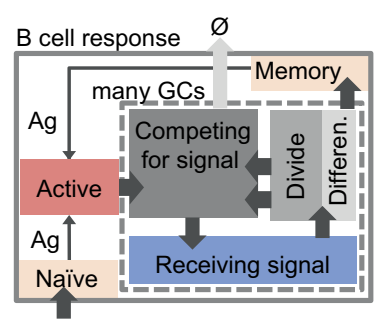

D

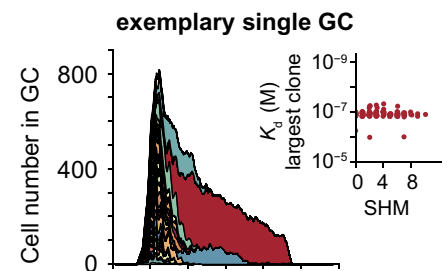

E

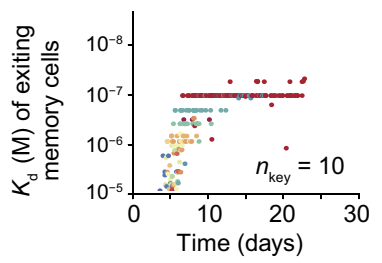

B

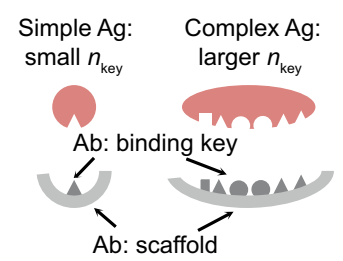

mean of 500 GCs
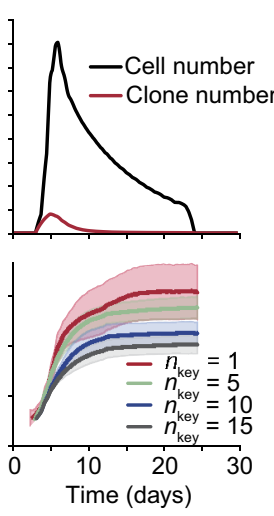

I
C

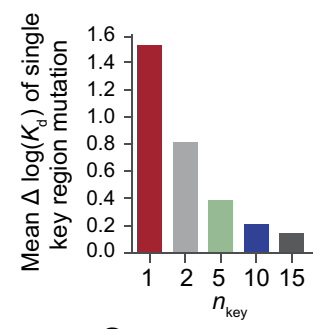

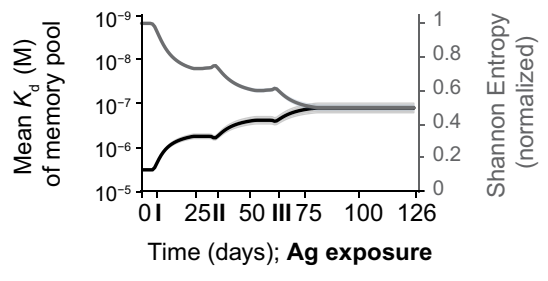

H

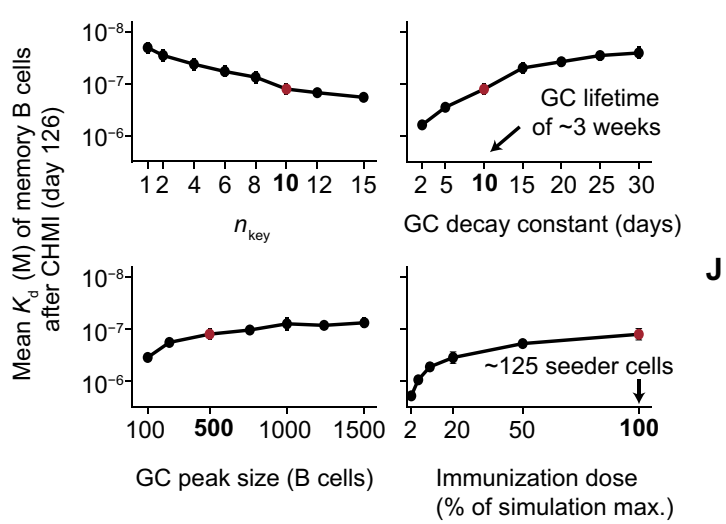

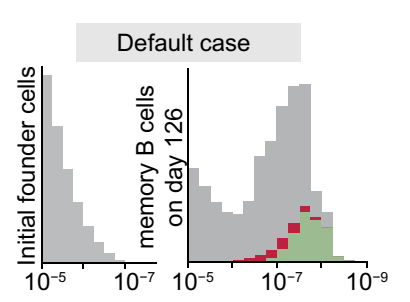

J

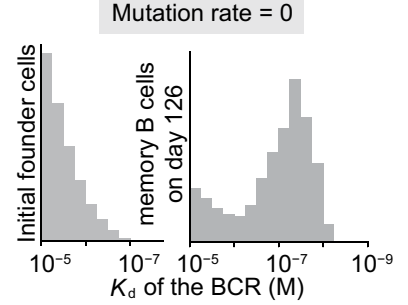

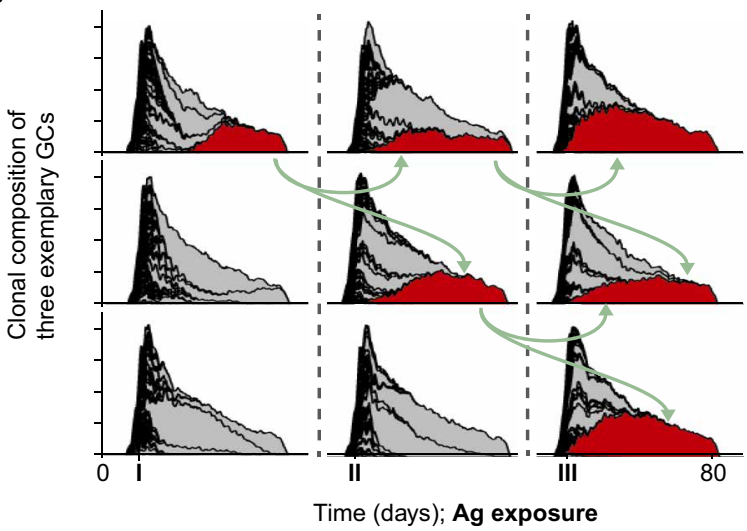

K

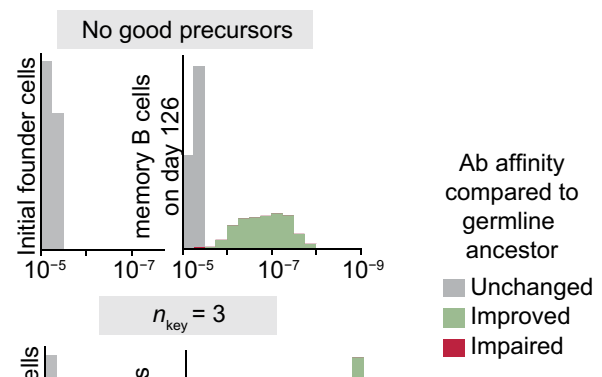

Fig. 3. Computational model of the B cell response to complex antigens. (A and B) Schemes of GC (A) and key mutation models (B). (C) Mean effect of single key mutations on $\log K_{d}$ for different $n_{\text {key }}$ values. (D) Clonal composition of one exemplary GC (left) and mean cell and clone numbers of $500 \mathrm{GCs}$ (right) over time. Colors indicate different clones. Inset: Affinity of individual memory cells stemming from the GC-dominating red clone over mutational state. (E) Left: Affinity of memory B cells produced by the GC reaction in (D). Colors indicate clones. Right: Affinity of GC memory output over time for different $n_{\text {key }}$ values. Mean of 500 simulations, shaded area $=1$ SD. (F) Dynamics of memory cell affinity and clonal diversity (normalized Shannon entropy) in a simulation of the experimental trial protocol (Fig.1A). Mean of 50 simulations, shaded area $=1$ SD. (G) Clonal composition of GCs after each infection. Clonally expanded high-affinity clones (red) seed and expand in successively more GCs after the second and third infection. (H) Sensitivity of the mean affinity $\left(K_{\mathrm{d}}\right)$ of the memory B cell pool after three infections to changes in $n_{\text {key, }}$ GC peak size, GC lifetime, and antigen dose. Means of 50 simulations, error bars = 1 SD. Default values are highlighted. (I to L) Affinity distribution in GC precursor cells at day 0 (left) and corresponding memory B cells after three infections at day 126 (right). (I) Default conditions for $n_{\text {key }}=10$ with a diverse precursor repertoire and natural mutation rate of 0.003 per codon and division. (J) As in (I), but with mutation rate of zero (no SHM possible). (K) As in (I), but limited repertoire without high-affinity GC precursors. (L) As in (I), but for a lower complexity antigen of $n_{\text {key }}=3$. Memory B cells with equal, higher, or lower affinity than their corresponding GC precursor are shown in gray, green, and red, respectively. Ab, antibody.

lost, leading to oligoclonal or monoclonal GCs (Fig. 3D), as previously observed (36). For larger epitope complexity, affinity maturation in an individual GC occurred predominantly through the selection of highaffinity seeders, whereas intraclonal affinity improvement was negligible [Fig. 3, D (inset) and E, and fig. S4].

To simulate the PfSPZ-CVac clinical trial, antigen was introduced at days 0,28 , and 56 into a model consisting of 50 GCs. After each exposure, we observed an increase in the mean binding affinity of the memory B cell pool accompanied by a decrease in diversity (Shannon entropy) due to the progressive expansion of high-affinity clones (Fig. 3F). These findings closely agree with the experimental data (Fig. 1, E to J). Subsequent boosts massively amplify high-affinity memory cells generated by the first or second response as they spread through and eventually dominate multiple GCs over time (Fig. 3G and 
fig. S5). We next computed how the mean affinity improvement was controlled by the parameters of the GC reaction and found strong dependence on antigen complexity $\left(n_{\text {key }}\right)$, GC lifetime, and diversity of seeding precursor $\mathrm{B}$ cells depending on the antigen dose, whereas GC peak size had less effect (Fig. 3H). In natural Plasmodium infection in vivo, GCs are disrupted at around day 7 by the emergence of bloodstage antigens (37); for the trial simulation, we assumed a limited but somewhat longer GC lifetime (about 3 weeks) due to the rapid elimination of blood stages by chloroquine (9). Thus, in addition to the relative structural complexity of PfCSP, the limited GC lifetime and the overall short time period of the trial are predicted to be strongly limiting factors for intraclonal affinity improvement.

To distinguish the contributions of clonal selection of highaffinity precursors from intraclonal affinity maturation, we analyzed how the initial affinity distribution of GC-seeding precursors becomes transformed under subsequent responses (Fig. 3, I to L). If the initial repertoire contains (rare) high-affinity binders (Fig. 3I, left), these will become enriched over time and contribute the bulk of the high-affinity memory cell population at the end of the trial (Fig. 3I, right, gray), with minor contributions of intraclonal affinity maturation by SHM (green). Even in the total absence of mutations, repeated GC reactions could thus produce a large high-affinity memory population from very few high-affinity precursors (Fig. 3J). However, if no high-affinity precursors are available, then SHM remains the only route for affinity improvement, resulting in a much lower fraction of high-affinity binders at the end of the simulated trial (Fig. 3K). This outcome strongly depends on antigen complexity because SHM is much more efficient in cases with low $n_{\text {key }}$ (Fig. $3 \mathrm{~L}$ ). Thus, our computational model argues that successful memory B cell responses rely both on high antigen dose to recruit large numbers of GC precursor cells and on repeated exposures, thereby allowing the best binders to avalanche through a large number of GCs.

\section{Protective high-affinity PfCSP NANP-reactive memory $B$ cells originate predominantly from unmutated precursors with specific Ig gene features}

To make a testable prediction, we analyzed simulated samples of memory B cells for antibody mutation count and affinity (Fig. 4A). Shortly after the first antigen exposure (I), many of the simulated memory B cells originated from earlier unrelated infections. GCs then selectively expanded the best precursor cells. These were increasingly more likely to derive from the large and continuously renewed pool of naïve B cells than from the limited number of available memory B cells. Thus, high-affinity memory B cells derived from naïve precursors were detected only after the second antigen exposure (II) and accumulated low levels of SHM after the third (III). Analysis of the experimental data confirmed these predictions (Fig. 4, $\mathrm{B}$ and $\mathrm{C}$ ). Some of the high-quality anti-PfCSP antibodies carried large numbers of SHM, suggesting that they developed from preexisting memory B cells. However, the most potent PfCSP inhibitory antibodies showed no or very low SHM counts in IGHV and IGKV or IGLV genes. In agreement with the model, such antibodies were first detected after the second exposure (II) and were more frequent after the third (III) but could also be detected after CHMI (fig. S6A).

To determine whether antibodies with high PfCSP reactivity had specific Ig gene features, we analyzed the Ig gene repertoire of PfCSP memory B cells in comparison with plasmablasts. Antibodies with high PfCSP reactivity were frequently encoded by IGHV3 family gene segments and featured Igא chains with 8-amino acid-long
CDR3 (KCDR3) (Fig. 4, D and E, and table S5). These antibodies were strongly enriched in the PfCSP memory compared with the plasmablast pool in donors T2_071-073 (fig. S6, B and C). A subset of anti-PfCSP antibodies with 8-amino acid-long KCDR3 showed high affinity $\left(K_{\mathrm{d}}<10^{-7} \mathrm{M}\right)$ for $\mathrm{NANP}_{5}$ and were all potent parasite inhibitors (Fig. 4F and fig. S6D). These antibodies originated almost exclusively from B cell clusters encoded by $I G H V 3-33$ in association with IGKV1-5 and, to a lesser extent, IGKV3-20 or IGKV3-11 genes (Fig. 4G). Passive immunization with a representative VH3-33/Vк1-5/ KCDR3:8 antibody $\left(1210 ; K_{\mathrm{d}}=1.14 \times 10^{-8} \mathrm{M}\right)$ from one of these clusters protected mice from infection with PfCSP-transgenic Plasmodium berghei parasites $[\mathrm{Pb}$-PfCSP; (35)] demonstrating the in vivo functional relevance and overall quality of these antibodies (Fig. $4 \mathrm{H})$. Unmutated or low-mutated high-affinity VH3-33 antibody clusters were readily detected after the second and/or third immunization in donors T2_071-073 (fig. S6E and table S5). In donor T2_042, such cells were detected at low frequency only at day 7 after CHMI, suggesting that their recruitment was comparably inefficient. High-affinity VH3-33 antibodies were not detected in any of the other donors. We conclude that high-affinity PfCSP-reactive memory B cells originate predominantly from unmutated precursors with specific Ig gene features. Combined, the degree of clonal expansion, frequency of Ig genes with 8-amino acid-long KCDR3, and IGHV3 family usage distinguished donors with low-quality (T2_017-035 and T2_051) from donors with high-quality (T2_042 and T2_071-073) anti-PfCSP responses (Fig. 4, I and J).

\section{DISCUSSION}

Our data suggest that the relative abundance and clonal selection of potent antigen binders will play a major role in the evolution of highaffinity memory B cell responses against PfCSP. An indirect effect of affinity maturation might be to broaden the memory B cell response, paralleling the effect of neutral genetic drift on organismic evolution or to improve binding to full-length PfCSP rather than the core NANP epitope alone (38). Future studies will have to assess the three-dimensional structure of PfCSP to define how the antibodies interact with the full-length protein and to determine how binding mode and affinity correlate with protection $(35,39,40)$. Individuals with naïve or memory B cells expressing high-affinity antibodies may have a selective advantage in mounting protective memory responses upon natural Pf infection or vaccination. The likelihood of recruiting potent precursors will increase if larger numbers of B cells are activated, thereby boosting the quality of the response. Repeated immunizations will help to activate, distribute, and expand memory B cells in newly formed GCs. Thus, inefficient affinity maturation to the NANP repeat is not caused by failure to select the best binders, for example because the affinity ceiling has been reached at which the cells cannot discriminate differences in antigen binding any more $(3,28)$. Instead, high-binding germline B cells outcompete rare antibody mutants with improved NANP affinity that developed by SHM from low-binding precursors.

Compared with many viral antigens, PfCSP appears to be an easy target for the humoral immune system because high-affinity antibody features are germline-encoded and potent precursors appear to be relatively abundant. However, sterile protection may require high anti-CSP titers to prevent the infection of liver cells, and the role of antibodies in CHMI protection after PfSPZ-CVac immunization remains to be determined. However, the protocol used much higher numbers of sporozoites compared with natural infections by 

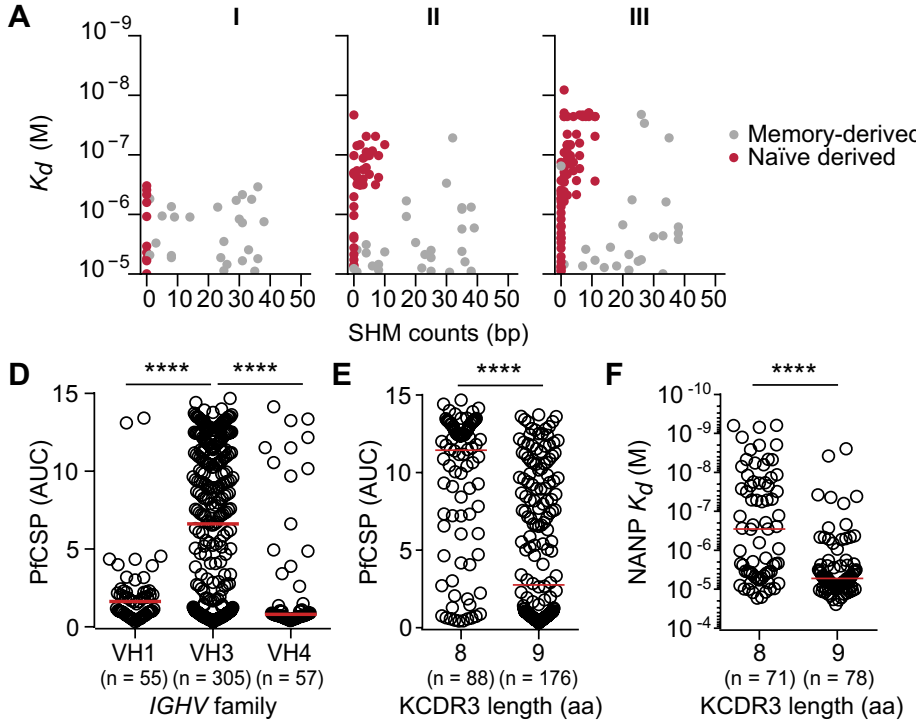

G

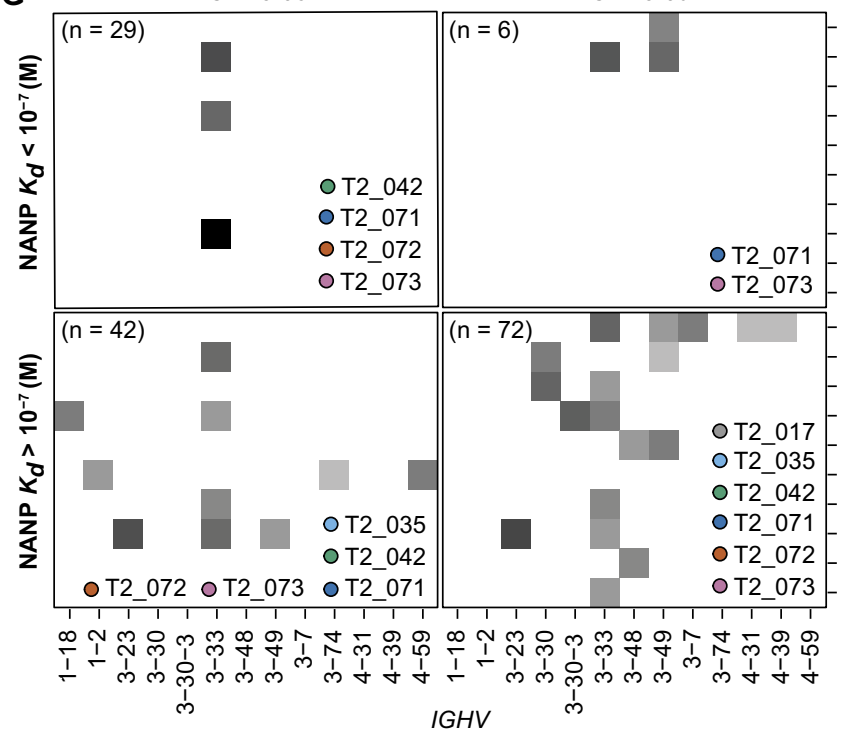

Memory-derived - Naïve derived

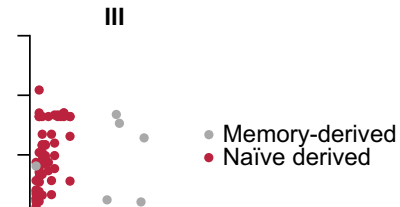
3-20

3-15 3-11 2D-29 2-28 $2-24$

$1-5$

12

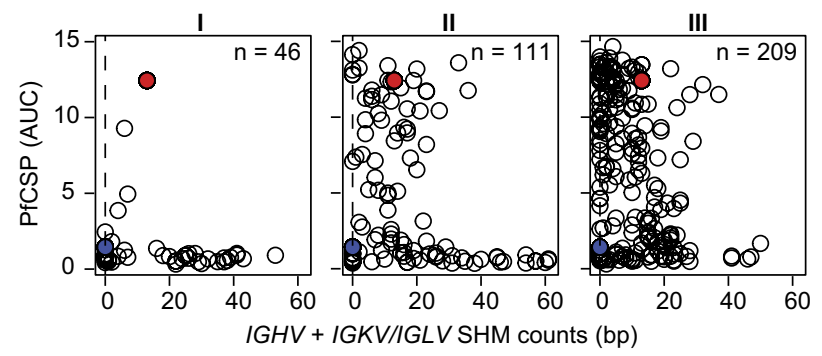

C

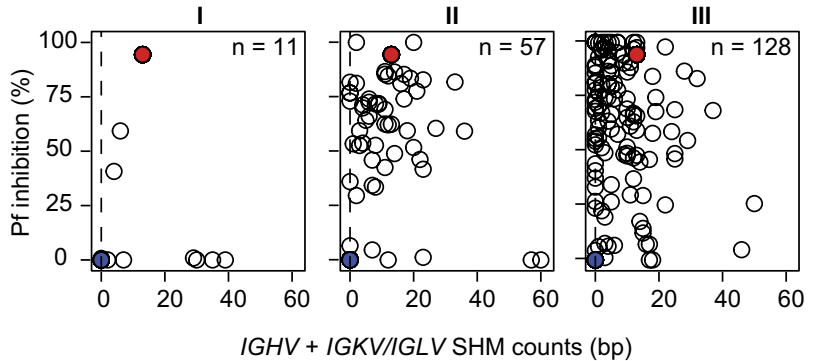

H

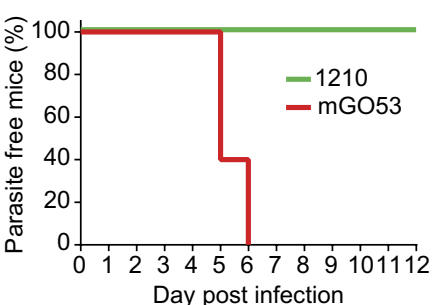

J

Day post infection
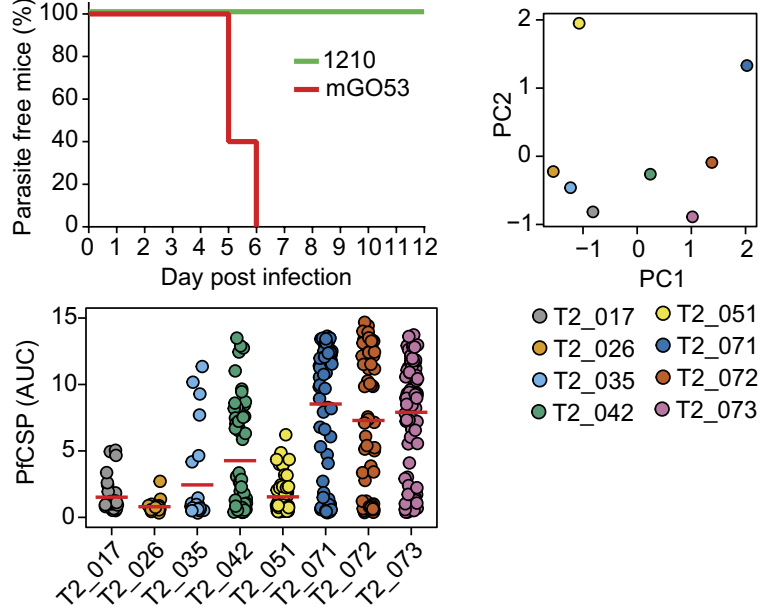

O T2_017 O T2_051 O T2 $026 \quad$ O T2 071 O T2_035 O T2_072 ○ T2_042 OT2_073

Fig. 4. Recruitment of potent germline antibodies after repeated Pf exposure. (A) Antibody affinity versus SHM as predicted by the mathematical model (Fig.3). Red and gray fillings indicate antibodies from memory B cells derived from clones that entered the Pf response as naïve or preexisting memory B cells, respectively. (B to $\mathbf{G}$ ) Ig gene features of memory B cell antibodies from eight donors. PfCSP ELISA AUC (B) and Pf sporozoite inhibition activity (C) versus total IGHV plus IGKV/IGLV SHM counts. Dotted lines indicate germline antibodies. $2 \mathrm{~A} 10$ (red) and mGO53 (blue) are shown as positive and negative controls, respectively. (D and E) PfCSP ELISA reactivity (AUC) versus IGHV family usage (D) and Ig $\mathrm{CDR3}$ (KCDR3) amino acid (aa) length (E). (F) NANP affinity for antibodies with 8- and 9-amino acid-long KCDR3s. (G) Frequencies of IGHV-IGKV gene association for antibodies with high $\left(<10^{-7} \mathrm{M}\right)$ and low $\left(>10^{-7} \mathrm{M}\right)$ NANP affinity and 8- or 9-amino acid-long KCDR3. $n$ indicates number of tested antibodies. Donors with observed antibody gene associations are listed. (H) Parasite-free mice after passive immunization and $P b$-PfCSP infection. $n=5$ per group. (I) Quality of PfCSP memory B cell antibodies from the indicated donors as measured by ELISA (AUC). $n$ numbers are as shown in table S1. (J) Principal components analysis based on mean degree of clonal expansion after three Pf exposures (Fig.1F, subsampling), frequency of antibodies expressing /GHV3 (fig. S6B), and frequency of antibodies with

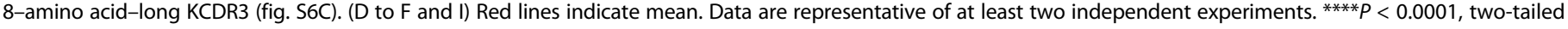
Mann-Whitney test.

mosquitoes, which are estimated to inject less than 100 sporozoites (9, 41-43). Further, chloroquine treatment eliminates blood-stage parasites (9). Therefore, the high sporozoite and relatively low bloodstage parasite load may focus the immune response toward sporozoite and liver-stage antigens (37). Strong memory B cell responses to PfCSP developed in some but not all donors, demonstrating that interdonor variability rather than the use of chloroquine influenced the quality of the response. Thus, although we cannot exclude that the immune response might have been stronger in the absence of chloroquine, we observed no evidence for impaired GC responses after PfSPZ-CVac, and the antibodies were potent parasite inhibitors in vitro and in vivo (35).

The generation of protective memory $\mathrm{B}$ cell responses to natural sporozoite infections may take much longer $(44,45)$. Repeated 
long-term antigen exposure might eventually compensate for the low antigen amounts, providing sufficient time to generate optimized antibodies by affinity maturation as shown for human PfCSP memory B cell antibodies induced by natural Pf exposure (35). PfCSP-based vaccine approaches may benefit from designing immunogens that efficiently target B cells expressing high-affinity germline anti-NANP repeat antibodies. Although our study focuses on malaria and PfCSP, our data show that the major rate-limiting step in affinity maturation is the number of key mutations necessary to improve antigen binding. Thus, the basic concepts that underlie the formation of high-affinity human memory B cell antibodies as defined in this study are likely more universal and may extend to B cell memory responses against other pathogens and antigens, for example, in cancer, autoimmunity, and vaccine design.

\section{MATERIALS AND METHODS \\ Study design and samples}

The study design details of the clinical trial have been described previously (9). In brief, peripheral blood samples from nine European donors with no history of malaria or HIV infection who had been exposed three times to 51,200 live, infectious, aseptic, purified, cryopreserved Pf NF54 sporozoites (Sanaria PfSPZ Challenge) by direct venous inoculation under chloroquine prophylaxis followed by CHMI with 3200 PfSPZ of PfSPZ Challenge in the absence of chloroquine during participation in PfSPZ-CVac clinical trial TÜCHMI-2 [Tübingen CHMI; ClinicalTrials.gov no. NCT02115516 (9)] were collected 7 days after each Pf exposure. Peripheral blood mononuclear cells (PBMCs) were isolated using Ficoll gradient density centrifugation and frozen.

\section{Flow cytometry and single-cell sorting}

Frozen PBMCs were thawed and washed twice with RPMI 1640 (Gibco). Recombinant NF54 PfCSP (Protein Potential LLC) was labeled with Alexa Fluor 647 Protein Labeling Kit (Molecular Probes). Single-cell suspensions were stained with CSP-Alexa Fluor 647 and the following mouse anti-human antibodies at the indicated dilutions: CD19Brilliant Violet 786 (BV786) (SJ25C1) at 1:10, CD20-allophycocyanin (APC)-H7 (2H7) at 1:20, CD27-phycoerythrin (PE) (M-T271) at 1:5, CD38-fluorescein isothiocyanate (FITC) (HIT2) at 1:5, IgG-BV510 (G18-145) at 1:20, CD138-BV421 (MI15) at 1:20 (all from BD Biosciences), and CD21-PE-Cy7 (Bu32) at 1:20 (BioLegend). 7-Aminoactinomycin $\mathrm{D}$ (7AAD) (Invitrogen) at 1:400 was used as dead cell marker. Single-cell sorting of $7 \mathrm{AAD}^{-} \mathrm{CSP}^{+} \mathrm{CD} 19^{+} \mathrm{B}$ cells gated positive for either IgG or $\mathrm{CD} 27$ as PfCSP memory B cells and $7 \mathrm{AAD}^{-} \mathrm{CD} 38^{+} \mathrm{CD} 27^{+} \mathrm{CD} 19^{+}$cells as plasmablasts was performed using FACSAria II (BD Biosciences) with FACSDiva software (version 8.0.1) using the index sort option. Data were analyzed using FlowJo v.10.0.8 (Tree Star).

\section{Matrix PCR amplification of Ig transcripts and sequence analysis}

$I G H, I G K$, and $I G L$ genes were amplified using a high-throughput robotic platform (46-48). In brief, complementary DNA was synthesized from sorted single cells using random hexamers. Ig genes were amplified using a nested matrix polymerase chain reaction (PCR) approach with barcoded primers in the second PCR (48). Amplicons were pooled, purified, and sequenced using the 454 GS FLX+ (Roche) or MiSeq $2 \times 300$-base pair (bp) paired-end (Illumina) sequencing platforms. sciReptor (version 1.0.1.-1-gad8bbdf or 1.0.2-0-gf70a308) was used for integrated analysis of Ig gene features and indexed flow cytometric data (49). Only wells with paired full-length functional Ig heavy and light chain gene sequences were analyzed.

\section{Recombinant monoclonal antibody production}

Recombinant monoclonal antibodies were generated as described previously (46). In brief, Ig genes from single B cells were amplified using restriction site-tagged $\mathrm{V}$ and J gene-specific primers and cloned into corresponding IgG 1 and Igא or Ig $\lambda$ expression vectors. Recombinant monoclonal antibodies were produced in human embryonic kidney (HEK) 293T (German Collection of Microorganisms and Cell Cultures, ACC-635) or HEK293F (Thermo Fisher Scientific) cells.

\section{Antibody purification and ELISA}

Recombinant monoclonal antibodies were purified and concentrations were measured by ELISA as described (46). Antigen-ELISAs and poly-ELISAs were performed as described $(35,46,50)$. In brief, high-binding polystyrene plates (Corning) were coated overnight at $4^{\circ} \mathrm{C}$ with Escherichia coli-expressed N-terminally truncated PfCSP (40 ng per well) [amino acids 123 to $411 ;(51)$ ], NANP 10 (50 ng per well) (Alpha Diagnostic International), double-stranded DNA (dsDNA) (150 ng per well) (Sigma), human insulin (150 ng per well) (Sigma), or lipopolysaccharide (LPS) (75 ng per well) (Sigma). Plates were blocked with $1 \%$ bovine serum albumin in phosphate-buffered saline (PBS) (PfCSP and NANP 10 ELISA) or with $0.01 \%$ Tween 20 and $0.01 \mathrm{M}$ EDTA in PBS (dsDNA, insulin, and LPS) for 1 hour at room temperature before antibody incubation at the indicated concentrations for 1.5 hours at room temperature. Anti-human IgG-horseradish peroxidase at 1:1000 (Jackson ImmunoResearch) in the corresponding blocking buffer and 1-Step ABTS substrate (Roche) were used for detection. For CSP-ELISAs, a chimeric version of the murine anti-PfCSP antibody $2 \mathrm{~A} 10(35,52)$ with human Ig heavy and Ig $\kappa$ constant regions and $\mathrm{mGO} 53$ (50) were used as positive and negative controls, respectively. For polyreactivity ELISAs, ED38 (53) and mGO53 were used as positive and negative controls, respectively. ELISA area under curve (AUC) values were calculated using GraphPad Prism 6.07 (GraphPad).

\section{Pf sporozoite hepatocyte traversal assay}

Anopheles coluzzi mosquitoes were reared and infected with Pf gametocytes (NF54 strain) as described by Triller et al. (35). In brief, salivary gland Pf sporozoites were preincubated with monoclonal antibodies $(100 \mu \mathrm{g} / \mathrm{ml})$ for $30 \mathrm{~min}$ on ice and incubated with human hepatocytes [HC-04; (54)] for 2 hours at $37^{\circ} \mathrm{C}$ and $5 \% \mathrm{CO}_{2}$ in the presence of dextran-rhodamine $(0.5 \mathrm{mg} / \mathrm{ml})$ (Molecular Probes). Nonantibody-treated $\mathrm{Pf}$ sporozoites were used to measure the maximum traversal capacity. Cells incubated only with dextran-rhodamine were used to determine the background. A chimeric version of $2 \mathrm{~A} 10$ (35) and mGO53 (50) were used as positive and negative controls, respectively. Cells were washed and fixed with $1 \%$ paraformaldehyde in PBS. Dextran positivity was detected using a FACS LSR II instrument (BD Biosciences). Data analysis was performed by background subtraction and normalization to the traversal capacity of Pf sporozoites not treated with any antibody using FlowJo v.10.0.8 (Tree Star).

\section{Surface plasmon resonance}

SPR measurements were performed with a Biacore T200 (GE Healthcare) instrument docked with series $\mathrm{S}$ sensor chip CM5 (GE Healthcare). Hepes $(10 \mathrm{mM})$ with $150 \mathrm{mM} \mathrm{NaCl}$ at $\mathrm{pH} 7.4$ was used as running buffer. Human antibody capture kit (GE Healthcare) was used for 
immobilization of anti-human IgG antibody by amine coupling following the manufacturer's instructions. Equal concentrations of the sample and control antibody [mGO53; (50)] were captured in the sample and reference flow cell, respectively. The flow cells were stabilized with running buffer at flow rate $(10 \mu \mathrm{l} / \mathrm{min})$ for $20 \mathrm{~min}$. NANP 5 (Alpha Diagnostic International) was dissolved in running buffer and injected at different concentrations: 0, 0.015, 0.09, 0.55, 3.3, and $20 \mu \mathrm{M}$. A flow rate of $30 \mu \mathrm{l} / \mathrm{min}$ was maintained, allowing the association and dissociation of $\mathrm{NANP}_{5}$ for 60 and $180 \mathrm{~s}$, respectively, at $25^{\circ} \mathrm{C}$. After each run, both flow cells were regenerated with $3 \mathrm{M} \mathrm{MgCl}_{2}$. The data were fit using 1:1 binding model or steady-state kinetic analysis using the Biacore T200 software version 2.0.

\section{Antibody germline reversion generation}

To generate germline versions of hypermutated antibodies, the respective $I G H, I G K$, or $I G L \mathrm{~V}$ regions were synthesized (Eurofins Genomics) using the germline sequence of the identified $\mathrm{V}$ - and J-gene segments. For the V(D)J junction region, the CDR3 sequence of the least mutated antibody of a B cell cluster was used. The synthesized $\mathrm{V}$ regions were cloned and expressed.

\section{In vivo mouse experiments}

Animal experiments were approved by the LAGeSo, Berlin, Germany (H0027/12). Eight-week-old C57BL/6 female mice were passively immunized intraperitoneally with $100 \mu \mathrm{g}$ of monoclonal human IgG1 antibody in $200 \mu \mathrm{l}$ of PBS. Twenty-four hours later, mice were infected with 5000 PfCSP transgenic P. berghei [Pb-PfCSP; (35)] sporozoites by subcutaneous injection at the tail base. Blood smears were prepared daily from day 3 to day 12 after infection. Blood parasitemia was determined using Giemsa staining. At least 100 microscopic fields were counted. Mice with blood-stage parasites were sacrificed 4 days after being tested positive.

\section{Mathematical model}

The GC-based memory B cell response to the CHMI trial protocol was simulated with an agent-based model written in Python 2.7 building on parameters from the experimental literature $(9,28-31,37,55-68)$. A detailed description of the model, the algorithm, and the parameters can be found in the Supplementary Materials.

\section{Statistics}

Experimental data were analyzed on Prism 6.07 (GraphPad) or RStudio (version 3.2.2) using two-tailed Mann-Whitney assuming non-normal distribution, $\chi^{2}$ test, or Fisher's exact test. Error bars indicate SEM. ${ }^{*} P<0.05,{ }^{* *} P<0.01,{ }^{* *} P<0.001,{ }^{* * * *} P<0.0001$. All experiments were performed in independently performed replicates, a minimum of twice.

\section{SUPPLEMENTARY MATERIALS}

immunology.sciencemag.org/cgi/content/full/3/20/eaap8029/DC1 Fig. S1. Anti-PfCSP response.

Fig. S2. PfCSP memory B cell Ig gene sequence analysis and antibody function. Fig. S3. Inefficient affinity maturation over repeated Pf exposure.

Fig. S4. Influence of GC seeder cell frequencies and antigen complexity $\left(n_{\text {key }}\right)$ on clonal evolution within individual GCs.

Fig. S5. Avalanche effect over three successive infections in an exemplary system of 10 different GC sites.

Fig. S6. Repertoire and Ig gene feature analysis of antibodies from PfCSP memory B cells and plasmablasts.

Table S1. Number of sequenced and cloned PfCSP-reactive memory B cell antibodies.

Table S2. Number of sequenced plasmablast antibodies.

Table S3. Clonally expanded PfCSP-reactive memory B cell clusters.
Table S4. Simulation parameters, binding model, GC simulation dynamics.

Table S5. PfCSP-reactive memory B cell antibodies with 8-amino acid-long KCDR3.

\section{REFERENCES AND NOTES}

1. M. A. Newman, C. R. Mainhart, C. P. Mallett, T. B. Lavoie, S. J. Smith-Gill, Patterns of antibody specificity during the BALB/C immune response to hen eggwhite lysozyme. J. Immunol. 149, 3260-3272 (1992).

2. H. P. Roost, M. F. Bachmann, A. Haag, U. Kalinke, V. Pliska, H. Hengartner, R. M. Zinkernagel, Early high-affinity neutralizing anti-viral lgG responses without further overall improvements of affinity. Proc. Natl. Acad. Sci. U.S.A. 92, 1257-1261 (1995).

3. J. Foote, H. N. Eisen, Kinetic and affinity limits on antibodies produced during immune responses. Proc. Natl. Acad. Sci. U.S.A. 92, 1254-1256 (1995).

4. G. D. Victora, M. C. Nussenzweig, Germinal centers. Annu. Rev. Immunol. 30, 429-457 (2012).

5. H. Mouquet, J. F. Scheid, M. J. Zoller, M. Krogsgaard, R. G. Ott, S. Shukair, M. N. Artyomov, J. Pietzsch, M. Connors, F. Pereyra, B. D. Walker, D. D. Ho, P. C. Wilson, M. S. Seaman, H. N. Eisen, A. K. Chakraborty, T. J. Hope, J. V. Ravetch, H. Wardemann, M. C. Nussenzweig, Polyreactivity increases the apparent affinity of anti-HIV antibodies by heteroligation. Nature 467, 591-595 (2010)

6. L. Pappas, M. Foglierini, L. Piccoli, N. L. Kallewaard, F. Turrini, C. Silacci, B. Fernandez-Rodriguez, G. Agatic, I. Giacchetto-Sasselli, G. Pellicciotta, F. Sallusto, Q. Zhu, E. Vicenzi, D. Corti, A. Lanzavecchia, Rapid development of broadly influenza neutralizing antibodies through redundant mutations. Nature 516, 418-422 (2014).

7. U. Wellmann, M. Letz, M. Herrmann, S. Angermüller, J. R. Kalden, T. H. Winkler, The evolution of human anti-double-stranded DNA autoantibodies. Proc. Natl. Acad. Sci. U.S.A. 102, 9258-9263 (2005).

8. A. H. Ellebedy, K. J. L. Jackson, H. T. Kissick, H. I. Nakaya, C. W. Davis, K. M. Roskin, A. K. McElroy, C. M. Oshansky, R. Elbein, S. Thomas, G. M. Lyon, C. F. Spiropoulou, A. K. Mehta, P. G. Thomas, S. D. Boyd, R. Ahmed, Defining antigen-specific plasmablast and memory $B$ cell subsets in human blood after viral infection or vaccination. Nat. Immunol. 17, 1226-1234 (2016).

9. B. Mordmüller, G. Surat, H. Lagler, S. Chakravarty, A. S. Ishizuka, A. Lalremruata, M. Gmeiner, J. J. Campo, M. Esen, A. J. Ruben, J. Held, C. L. Calle, J. B. Mengue, T. Gebru, J. Ibáñez, M. Sulyok, E. R. James, P. F. Billingsley, K. C. Natasha, A. Manoj, T. Murshedkar, A. Gunasekera, A. G. Eappen, T. Li, R. E. Stafford, M. Li, P. L. Felgner, R. A. Seder, T. L. Richie, B. K. L. Sim, S. L. Hoffman, P. G. Kremsner, Sterile protection against human malaria by chemoattenuated PfSPZ vaccine. Nature 542, 445-449 (2017).

10. M. Roestenberg, M. McCall, J. Hopman, J. Wiersma, A. J. Luty, G. J. van Gemert, M. van de Vegte-Bolmer, B. van Schaijk, K. Teelen, T. Arens, L. Spaarman, Q. de Mast, W. Roeffen, G. Snounou, L. Rénia, A. van der Ven, C. C. Hermsen, R. Sauerwein, Protection against a malaria challenge by sporozoite inoculation. N. Engl. J. Med. 361, 468-477 (2009).

11. S. H. Sheehy, A. J. Spencer, A. D. Douglas, B. K. L. Sim, R. J. Longley, N. J. Edwards, I. D. Poulton, D. Kimani, A. R. Williams, N. A. Anagnostou, R. Roberts, S. Kerridge, M. Voysey, E. R. James, P. F. Billingsley, A. Gunasekera, A. M. Lawrie, S. L. Hoffman, A. V. S. Hill, Optimising controlled human malaria infection studies using cryopreserved P. falciparum parasites administered by needle and syringe. PLOS ONE 8, e65960 (2013).

12. A. S. Ishizuka, K. E. Lyke, A. DeZure, A. A. Berry, T. L. Richie, F. H. Mendoza, M. E. Enama, I. J. Gordon, L.-J. Chang, U. N. Sarwar, K. L. Zephir, L. S. A. Holman, E. R. James, P. F. Billingsley, A. Gunasekera, S. Chakravarty, A. Manoj, M. L. Li, A. J. Ruben, T. Li, A. G. Eappen, R. E. Stafford, K. C. Natasha, T. Murshedkar, H. DeCederfelt, S. H. Plummer, C. S. Hendel, L. Novik, P. J. M. Costner, J. G. Saunders, M. B. Laurens, C. V. Plowe, B. Flynn, W. R. Whalen, J. P. Todd, J. Noor, S. Rao, K. Sierra-Davidson, G. M. Lynn, J. E. Epstein, M. A. Kemp, G. A. Fahle, S. A. Mikolajczak, M. Fishbaugher, B. K. Sack, S. H. I. Kappe, S. A. Davidson, L. S. Garver, N. K. Björkström, M. C. Nason, B. S. Graham, M. Roederer, B. K. L. Sim, S. L. Hoffman, J. E. Ledgerwood, R. A. Seder, Protection against malaria at 1 year and immune correlates following PfSPZ vaccination. Nat. Med. 22, 614-623 (2016).

13. K. E. Lyke, A. S. Ishizuka, A. A. Berry, S. Chakravarty, A. DeZure, M. E. Enama, E. R. James, P. F. Billingsley, A. Gunasekera, A. Manoj, M. Li, A. J. Ruben, T. Li, A. G. Eappen, R. E. Stafford, N. KC, T. Murshedkar, F. H. Mendoza, I. J. Gordon, K. L. Zephir L. S. A. Holman, S. H. Plummer, C. S. Hendel, L. Novik, P. J. M. Costner, J. G. Saunders, N. M. Berkowitz, B. J. Flynn, M. C. Nason, L. S. Garver, M. B. Laurens, C. V. Plowe, T. L. Richie, B. S. Graham, M. Roederer, B. K. L. Sim, J. E. Ledgerwood, S. L. Hoffman, R. A. Seder, Attenuated PfSPZ Vaccine induces strain-transcending $T$ cells and durable protection against heterologous controlled human malaria infection. Proc. Natl. Acad. Sci. U.S.A. 114, 2711-2716 (2017).

14. J. E. Epstein, K. M. Paolino, T. L. Richie, M. Sedegah, A. Singer, A. J. Ruben, S. Chakravarty A. Stafford, R. C. Ruck, A. G. Eappen, T. Li, P. F. Billingsley, A. Manoj, J. C. Silva, K. Moser, R. Nielsen, D. Tosh, S. Cicatelli, H. Ganeshan, J. Case, D. Padilla, S. Davidson, L. Garver, 
E. Saverino, T. Murshedkar, A. Gunasekera, P. S. Twomey, S. Reyes, J. E. Moon, E. R. James, K. C. Natasha, M. Li, E. Abot, A. Belmonte, K. Hauns, M. Belmonte, J. Huang, C. Vasquez, S. Remich, M. Carrington, Y. Abebe, A. Tillman, B. Hickey, J. Regules, E. Villasante, B. K. L. Sim, S. L. Hoffman, Protection against Plasmodium falciparum malaria by PfSPZ Vaccine. JCI Insight 2, e89154 (2017).

15. M. S. Sissoko, S. A. Healy, A. Katile, F. Omaswa, I. Zaidi, E. E. Gabriel, B. Kamate, Y. Samake, M. A. Guindo, A. Dolo, A. Niangaly, K. Niaré, A. Zeguime, K. Sissoko, H. Diallo, I. Thera, K. Ding, M. P. Fay, E. M. O'Connell, T. B. Nutman, S. Wong-Madden, T. Murshedkar, A. J. Ruben, M. Li, Y. Abebe, A. Manoj, A. Gunasekera, S. Chakravarty, B. K. L. Sim, P. F. Billingsley, E. R. James, M. Walther, T. L. Richie, S. L. Hoffman, O. Doumbo, P. E. Duffy, Safety and efficacy of PfSPZ Vaccine against Plasmodium falciparum via direct venous inoculation in healthy malaria-exposed adults in Mali: A randomised, double-blind phase 1 trial. Lancet Infect. Dis. 17, 498-509 (2017).

16. N. Yoshida, R. S. Nussenzweig, P. Potocnjak, V. Nussenzweig, M. Aikawa, Hybridoma produces protective antibodies directed against the sporozoite stage of malaria parasite. Science 207, 71-73 (1980).

17. P. Potocnjak, N. Yoshida, R. S. Nussenzweig, V. Nussenzweig, Monovalent fragments (Fab) of monoclonal antibodies to a sporozoite surface antigen ( $\mathrm{Pb} 44)$ protect mice against malarial infection. J. Exp. Med. 151, 1504-1513 (1980).

18. L. Foquet, C. C. Hermsen, G.-J. van Gemert, E. Van Braeckel, K. E. Weening, R. Sauerwein, P. Meuleman, G. Leroux-Roels, Vaccine-induced monoclonal antibodies targeting circumsporozoite protein prevent Plasmodium falciparum infection. J. Clin. Invest. 124, 140-144 (2014).

19. B. K. Sack, J. L. Miller, A. M. Vaughan, A. Douglass, A. Kaushansky, S. Mikolajczak, A. Coppi, G. Gonzalez-Aseguinolaza, M. Tsuji, F. Zavala, P. Sinnis, S. H. I. Kappe, Model for in vivo assessment of humoral protection against malaria sporozoite challenge by passive transfer of monoclonal antibodies and immune serum. Infect. Immun. 82, 808-817 (2014).

20. Y. Charoenvit, W. E. Collins, T. R. Jones, P. Millet, L. Yuan, G. H. Campbell, R. L. Beaudoin, J. R. Broderson, S. L. Hoffman, Inability of malaria vaccine to induce antibodies to a protective epitope within its sequence. Science 251, 668-671 (1991).

21. Y. Charoenvit, S. Mellouk, C. Cole, R. Bechara, M. F. Leef, M. Sedegah, L. F. Yuan, F. A. Robey, R. L. Beaudoin, S. L. Hoffman, Monoclonal, but not polyclonal, antibodies protect against Plasmodium yoelii sporozoites. J. Immunol. 146, 1020-1025 (1991).

22. M. Roestenberg, E. M. Bijker, B. K. L. Sim, P. F. Billingsley, E. R. James, G. J. H. Bastiaens, A. C. Teirlinck, A. Scholzen, K. Teelen, T. Arens, A. J. A. M. van der Ven, A. Gunasekera, S. Chakravarty, S. Velmurugan, C. C. Hermsen, R. W. Sauerwein, S. L. Hoffman, Controlled human malaria infections by intradermal injection of cryopreserved Plasmodium falciparum sporozoites. Am. J. Trop. Med. Hyg. 88, 5-13 (2013).

23. B. Mordmüller, C. Supan, K. L. Sim, G. P. Gómez-Pérez, C. L. Ospina Salazar, J. Held, S. Bolte, M. Esen, S. Tschan, F. Joanny, C. L. Calle, S. J. Z. Löhr, A. Lalremruata, A. Gunasekera, E. R. James, P. F. Billingsley, A. Richman, S. Chakravarty, A. Legarda, J. Muñoz, R. M. Antonijoan, M. Rosa Ballester, S. L. Hoffman, P. L. Alonso, P. G. Kremsner, Direct venous inoculation of Plasmodium falciparum sporozoites for controlled human malaria infection: A dose-finding trial in two centres. Malar. J. 14, 117 (2015).

24. M. Tsuiji, S. Yurasov, K. Velinzon, S. Thomas, M. C. Nussenzweig, H. Wardemann, A checkpoint for autoreactivity in human $\lg \mathrm{M}^{+}$memory $\mathrm{B}$ cell development. J. Exp. Med. 203, 393-400 (2006).

25. T. Tiller, M. Tsuiji, S. Yurasov, K. Velinzon, M. C. Nussenzweig, H. Wardemann, Autoreactivity in human Ig G $^{+}$memory B cells. Immunity 26, 205-213 (2007).

26. M. A. Berkowska, J.-N. Schickel, C. Grosserichter-Wagener, D. de Ridder, Y. S. Ng, J. J. M. van Dongen, E. Meffre, M. C. van Zelm, Circulating human CD27- $\lg A^{+}$memory B cells recognize bacteria with polyreactive Igs. J. Immunol. 195, 1417-1426 (2015).

27. J. Prigent, V. Lorin, A. Kök, T. Hieu, S. Bourgeau, H. Mouquet, Scarcity of autoreactive human blood Ig A ${ }^{+}$memory B cells. Eur. J. Immunol. 46, 2340-2351 (2016).

28. F. D. Batista, M. S. Neuberger, Affinity dependence of the $B$ cell response to antigen: A threshold, a ceiling, and the importance of off-rate. Immunity 8, 751-759 (1998).

29. D. McKean, K. Huppi, M. Bell, L. Staudt, W. Gerhard, M. Weigert, Generation of antibody diversity in the immune response of $B A L B / c$ mice to influenza virus hemagglutinin. Proc. Natl. Acad. Sci. U.S.A. 81, 3180-3184 (1984).

30. C. D. C. Allen, T. Okada, H. L. Tang, J. G. Cyster, Imaging of germinal center selection events during affinity maturation. Science 315, 528-531 (2007).

31. S. H. Kleinstein, Y. Louzoun, M. J. Shlomchik, Estimating hypermutation rates from clonal tree data. J. Immunol. 171, 4639-4649 (2003).

32. D. Allen, T. Simon, F. Sablitzky, K. Rajewsky, A. Cumano, Antibody engineering for the analysis of affinity maturation of an anti-hapten response. EMBO J. 7, 1995-2001 (1988).

33. C. Berek, A. Berger, M. Apel, Maturation of the immune response in germinal centers. Cell 67, 1121-1129 (1991)

34. C. Kocks, K. Rajewsky, Stepwise intraclonal maturation of antibody affinity through somatic hypermutation. Proc. Natl. Acad. Sci. U.S.A. 85, 8206-8210 (1988).

35. G. Triller, S. W. Scally, G. Costa, M. Pissarev, C. Kreschel, A. Bosch, E. Marois, B. K. Sack, R. Murugan, A. M. Salman, C. J. Janse, S. M. Khan, S. H. I. Kappe, A. A. Adegnika,
B. Mordmüller, E. A. Levashina, J.-P. Julien, H. Wardemann, Natural parasite exposure induces protective human anti-malarial antibodies. Immunity 47, 1197-1209 (2017).

36. J. M. J. Tas, L. Mesin, G. Pasqual, S. Targ, J. T. Jacobsen, Y. M. Mano, C. S. Chen, J.-C. Weill, C.-A. Reynaud, E. P. Browne, M. Meyer-Hermann, G. D. Victora, Visualizing antibody affinity maturation in germinal centers. Science 351, 1048-1054 (2016).

37. G. J. Keitany, K. S. Kim, A. T. Krishnamurty, B. D. Hondowicz, W. O. Hahn, N. Dambrauskas, D. Noah Sather, A. M. Vaughan, S. H. I. Kappe, M. Pepper, Blood stage malaria disrupts humoral immunity to the pre-erythrocytic stage circumsporozoite protein. Cell Rep. 17, 3193-3205 (2016).

38. M. Kimura, Evolutionary rate at the molecular level. Nature 217, 624-626 (1968).

39. C. R. Fisher, H. J. Sutton, J. A. Kaczmarski, H. A. McNamara, B. Clifton, J. Mitchell, Y. Cai, J. N. Dups, N. J. DArcy, M. Singh, A. Chuah, T. S. Peat, C. J. Jackson, I. A. Cockburn, T-dependent $\mathrm{B}$ cell responses to Plasmodium induce antibodies that form a high-avidity multivalent complex with the circumsporozoite protein. PLOS Pathog. 13, e1006469 (2017).

40. D. Oyen, J. L. Torres, U. Wille-Reece, C. F. Ockenhouse, D. Emerling, J. Glanville, W. Volkmuth, Y. Flores-Garcia, F. Zavala, A. B. Ward, C. R. King, I. A. Wilson, Structural basis for antibody recognition of the NANP repeats in Plasmodium falciparum circumsporozoite protein. Proc. Natl. Acad. Sci. U.S.A. 48, E10438-E10445 (2017)

41. R. Rosenberg, R. A. Burge, I. Schneider, R. Burge, An estimation of the number of malaria sporozoites ejected by a feeding mosquito. Trans. R. Soc. Trop. Med. Hyg. 84, 209-212 (1990).

42. J. C. Beier, J. R. Davis, J. A. Vaughan, B. H. Noden, M. S. Beier, Quantitation of Plasmodium falciparum sporozoites transmitted in vitro by experimentally infected Anopheles gambiae and Anopheles stephensi. Am. J. Trop. Med. Hyg. 44, 564-570 (1991).

43. J. P. Vanderberg, Imaging mosquito transmission of Plasmodium sporozoites into the mammalian host: Immunological implications. Parasitol. Int. 63, 150-164 (2014).

44. E. M. Riley, V. A. Stewart, Immune mechanisms in malaria: New insights in vaccine development. Nat. Med. 19, 168-178 (2013).

45. S. Portugal, S. K. Pierce, P. D. Crompton, Young lives lost as B cells falter: What we are learning about antibody responses in malaria. J. Immunol. 190, 3039-3046 (2013).

46. T. Tiller, E. Meffre, S. Yurasov, M. Tsuiji, M. C. Nussenzweig, H. Wardemann, Efficient generation of monoclonal antibodies from single human B cells by single cell RT-PCR and expression vector cloning. J. Immunol. Methods 329, 112-124 (2008).

47. R. Murugan, K. Imkeller, C. E. Busse, H. Wardemann, Direct high-throughput amplification and sequencing of immunoglobulin genes from single human B cells. Eur. J. Immunol. 45, 2698-2700 (2015).

48. C. E. Busse, I. Czogiel, P. Braun, P. F. Arndt, H. Wardemann, Single-cell based high-throughput sequencing of full-length immunoglobulin heavy and light chain genes. Eur. J. Immunol. 44, 597-603 (2014).

49. K. Imkeller, P. F. Arndt, H. Wardemann, C. E. Busse, sciReptor: Analysis of single-cell level immunoglobulin repertoires. BMC Bioinformatics 17, 67 (2016).

50. H. Wardemann, S. Yurasov, A. Schaefer, J. W. Young, E. Meffre, M. C. Nussenzweig, Predominant autoantibody production by early human B cell precursors. Science $\mathbf{3 0 1}$, 1374-1377 (2003).

51. K. Tewari, B. J. Flynn, S. B. Boscardin, K. Kastenmueller, A. M. Salazar, C. A. Anderson, V. Soundarapandian, A. Ahumada, T. Keler, S. L. Hoffman, M. C. Nussenzweig, R. M. Steinman, R. A. Seder, Poly $(\mathrm{l}: \mathrm{C})$ is an effective adjuvant for antibody and multi-functional CD4+ T cell responses to Plasmodium falciparum circumsporozoite

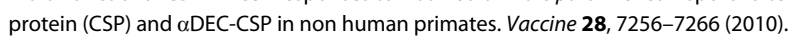

52. F. Zavala, A. H. Cochrane, E. H. Nardin, R. S. Nussenzweig, V. Nussenzweig, Circumsporozoite proteins of malaria parasites contain a single immunodominant region with two or more identical epitopes. J. Exp. Med. 157, 1947-1957 (1983).

53. E. Meffre, A. Schaefer, H. Wardemann, P. Wilson, E. Davis, M. C. Nussenzweig, Surrogate light chain expressing human peripheral B cells produce self-reactive antibodies. J. Exp. Med. 199, 145-150 (2004).

54. J. Sattabongkot, N. Yimamnuaychoke, S. Leelaudomlipi, M. Rasameesoraj, R. Jenwithisuk, R. E. Coleman, R. Udomsangpetch, L. Cui, T. G. Brewer, Establishment of a human hepatocyte line that supports in vitro development of the exo-erythrocytic stages of the malaria parasites Plasmodium falciparum and P. vivax. Am. J. Trop. Med. Hyg. 74, 708-715 (2006).

55. M. J. Shlomchik, P. Watts, M. G. Weigert, S. Litwin, Clone: A Monte-Carlo computer simulation of $B$ cell clonal expansion, somatic mutation, and antigen-driven selection. Curr. Top. Microbiol. Immunol. 229, 173-197 (1998).

56. P. D. Thomas, K. A. Dill, An iterative method for extracting energy-like quantities from protein structures. Proc. Natl. Acad. Sci. U.S.A. 93, 11628-11633 (1996).

57. R. M. Adams, J. B. Kinney, T. Mora, A. M. Walczak, Measuring the sequence-affinity landscape of antibodies with massively parallel titration curves. elife 5, e23156 (2016).

58. N. Wittenbrink, A. Klein, A. A. Weiser, J. Schuchhardt, M. Or-Guil, Is there a typical germinal center? A large-scale immunohistological study on the cellular composition of germinal centers during the hapten-carrier-driven primary immune response in mice. J. Immunol. 187, 6185-6196 (2011). 
59. T. E. Mandel, R. P. Phipps, A. Abbot, J. G. Tew, The follicular dendritic cell: Long term antigen retention during immunity. Immunol. Rev. 53, 29-59 (1980).

60. F. J. Weisel, G. V. Zuccarino-Catania, M. Chikina, M. J. Shlomchik, A temporal switch in the germinal center determines differential output of memory $B$ and plasma cells. Immunity 44, 116-130 (2016)

61. N. S. De Silva, U. Klein, Dynamics of B cells in germinal centres. Nat. Rev. Immunol. 15 137-148 (2015).

62. A. D. Gitlin, Z. Shulman, M. C. Nussenzweig, Clonal selection in the germinal centre by regulated proliferation and hypermutation. Nature 509, 637-640 (2014).

63. C. D. C. Allen, T. Okada, J. G. Cyster, Germinal-center organization and cellular dynamics. Immunity 27, 190-202 (2007).

64. D. C. Macallan, D. L. Wallace, Y. Zhang, H. Ghattas, B. Asquith, C. de Lara, A. Worth, G. Panayiotakopoulos, G. E. Griffin, D. F. Tough, P. C. L. Beverley, B-cell kinetics in humans: Rapid turnover of peripheral blood memory cells. Blood 105, 3633-3640 (2005).

65. M. Meyer-Hermann, E. Mohr, N. Pelletier, Y. Zhang, G. D. Victora, K.-M. Toellner, A theory of germinal center B cell selection, division, and exit. Cell Rep. 2, 162-174 (2012).

66. S. Chaudhury, J. Reifman, A. Wallqvist, Simulation of B cell affinity maturation explains enhanced antibody cross-reactivity induced by the polyvalent malaria vaccine AMA1. J. Immunol. 193, 2073-2086 (2014).

67. L. M. Childs, E. B. Baskerville, S. Cobey, Trade-offs in antibody repertoires to complex antigens. Philos. Trans. R. Soc. Lond. B Biol. Sci. 370, 20140245 (2015).

68. N. Wittenbrink, T. S. Weber, A. Klein, A. A. Weiser, W. Zuschratter, M. Sibila, J. Schuchhardt, M. Or-Guil, Broad volume distributions indicate nonsynchronized growth and suggest sudden collapses of germinal center B cell populations. J. Immunol. 184, 1339-1347 (2010).

Acknowledgments: We thank T. Kaiser (German Rheumatism Research Center, Berlin), B. Timmermann and S. Klages (Max Planck Institute for Molecular Genetics, Berlin), D. Foster and S. Kocher [German Cancer Research Center (DKFZ), Heidelberg], L. Spohr, D. Eyermann, and M. Andres (Max Planck Institute for Infection Biology, Berlin), the DKFZ/European Molecular Biology Laboratory (EMBL)/Heidelberg University Chemical Biology Core Facility (especially P. Sehr), and the DKFZ High-Throughput Sequencing Unit of the Genomics and Proteomics Core Facility for technical assistance and services. We thank the vaccine trial participants and all members of the clinical trial platform for their contribution and commitment to vaccine research. We thank the Sanaria and Protein Potential teams for manufacture and shipping of investigational products; PfSPZ Challenge and diluents, regulatory, quality, and clinical site activities; and legal and administrative support. We appreciate the expert reviews of the Safety Monitoring Committee (W. Chen, P. Coyne, and P. Zanger). The following reagent was obtained from BEI Resources, National Institute of Allergy and Infectious Diseases (NIAID), NIH: HC-04, Hepatocyte (human), MRA-975, contributed by J. S. Prachumsri. Funding: This work was supported by the German Research Foundation (DFG) GRK1121 (H.W.), Federal Ministry of Education and Research (BMBF) (PB12204, T.H.), and DFG (EXC81 CellNetworks, T.H.). The clinical trial was funded by the German Federal Ministry of Education and Research (BMBF) through the German Center for Infection Research (DZIF). Manufacture of investigational product by Sanaria was supported in part by the NIAID of the NIH under Small Business Innovation Research award nos. 5R44AI058375 and 5R44AI055229. Author contributions: R.M., G.C., E.A.L., and H.W. designed experiments. R.M., G.T., C.K., G.C and G.P.M. performed experiments. R.M., G.T., and H.W. analyzed experimental data. R.M. performed statistical analyses. L.B. and T.H. developed mathematical models and performed theoretical analyses. K.I. and C.E.B. developed bioinformatics tools and provided bioinformatics support. S.C., B.K.L.S., S.L.H., P.G.K., and B.M. provided clinical trial samples. B.M., T.H., and H.W. conceived the study. R.M., L.B., E.A.L., T.H., and H.W. wrote the manuscript. Competing interests: S.C., B.K.L.S., and S.L.H. are salaried employees of Sanaria Inc., the owner of the PfSPZ Challenge Vaccine and the sponsor of the clinical trial. B.K.L.S. and S.L.H. have financial interest in Sanaria Inc. All other authors declare that they have no competing interests. Data and materials availability: Data and materials will be available upon reasonable request under material transfer agreements. The source code of the vaccination simulation is publicly available at https://github.com/ LiBuchauer/gc_memo (doi:10.5281/zenodo.1048052).

Submitted 29 August 2017

Accepted 30 November 2017

Published 16 February 2018

10.1126/sciimmunol.aap8029

Citation: R. Murugan, L. Buchauer, G. Triller, C. Kreschel, G. Costa, G. Pidelaserra Martí, K. Imkeller, C.E. Busse, S. Chakravarty, B. K. L. Sim, S. L. Hoffman, E. A. Levashina, P. G. Kremsner, B. Mordmüller, T. Höfer, H. Wardemann, Clonal selection drives protective memory B cell responses in controlled human malaria infection. Sci. Immunol. 3, eaap8029 (2018). 


\section{ScienceImmunology}

\section{Clonal selection drives protective memory B cell responses in controlled human malaria infection}

Rajagopal Murugan, Lisa Buchauer, Gianna Triller, Cornelia Kreschel, Giulia Costa, Gemma Pidelaserra Martí, Katharina Imkeller, Christian E. Busse, Sumana Chakravarty, B. Kim Lee Sim, Stephen L. Hoffman, Elena A. Levashina, Peter G. Kremsner, Benjamin Mordmüller, Thomas Höfer and Hedda Wardemann

Sci. Immunol. 3, eaap8029.

DOI: $10.1126 /$ sciimmunol.aap8029

\section{Memories of exposure}

Protective memory B cell responses are shaped through multiple mechanisms, including clonal selection of naïve $B$ cells and affinity maturation. Memory B cell responses are considered critical to the development of a successful malaria vaccine, and Murugan et al. characterize memory B cell responses to the Plasmodium falciparum circumsporozoite (PfCSP) protein in human volunteers immunized with sporozoites. They observed that repeated immunization induced potent responses to the immunodominant PfCSP NANP repeat by the clonal selection of naïve and preexisting memory B cell precursors and was less influenced by affinity maturation. Computational modeling indicated that these responses are shaped by the complexity of the antigen, and these findings provide a new perspective on protective B cell responses.

ARTICLE TOOLS

SUPPLEMENTARY

MATERIALS

REFERENCES http://immunology.sciencemag.org/content/3/20/eaap8029

http://immunology.sciencemag.org/content/suppl/2018/02/13/3.20.eaap8029.DC1

This article cites 68 articles, 29 of which you can access for free http://immunology.sciencemag.org/content/3/20/eaap8029\#BIBL 